\title{
RODRIGUES, Cândido y PEIXOTO, Renato Amado (organizadores) Olhares sobre os catolicismos no Centro-Oeste, Nordeste e Norte do Brasil, EdUFMT, Cuiabá, 2016, 396 pp. ISBN 978-85-327-0580-8.
}

\author{
M. Florencia Contardo \\ Instituto de Historia Argentina y Americana "Dr. Emilio Ravignani", Consejo Nacional de \\ Investigaciones Científicas y Técnicas (CONICET) - Universidad de Buenos Aires (UBA), \\ Argentina \\ flor contardo@hotmail.com
}

Esta obra se publica bajo licencia Creative Commons Atribución-NoComercial-CompartirIgual 4.0 Internacional

\section{(c) EY-NC-SA}

La presente obra es una compilación realizada por los historiadores brasileños Cândido Rodrigues y Renato Amado Peixoto, dos de los fundadores de la Rede de Pesquisa História e Catolicismo no Mundo Contemporâneo (RHC). Esta red, de la cual participan muchos de los autores de este libro, fue creada en el año 2015 con el propósito de promover el diálogo y el intercambio entre investigadores, brasileños y extranjeros, interesados en el estudio del catolicismo contemporáneo. Este libro se inscribe como una continuación de aquellos publicados previamente por el núcleo fundador de la RHC: Catolicismos e sociabilidade intelectual no Brasil e na Argentina ${ }^{1}$ y Manifestações do Pensamento Católico na América do Sul. ${ }^{2}$

El título de la obra refleja bien su contenido en tanto prima la heterogeneidad, la pluralidad y el foco regional. El libro reúne dieciséis contribuciones, un prefacio y una presentación. Los autores de cada capítulo son investigadores, docentes o doctorandos de espacios de producción académica alejados de los tradicionales de San Pablo y Río de Janeiro. De este modo, están representadas universidades federales tan lejanas como las de Alagoas (UFAL), Amapá (UNIFAP), Bahía (UFBA), Ceará (UFC), Mato Grosso (UFMT), Rio Grande do Norte (UFRN) y Roraima (UFRR); y estaduales como las de Goiás (UEG) y Pernambuco (UPE).

De igual modo, la heterogeneidad se vislumbra en los abordajes teóricos, en los actores sociales elegidos y en los temas estudiados. El catolicismo es presentado como un fenómeno plural, multifacético, "sincrético" y de fronteras permeables, y de allí la elección de colocar como objeto de reflexión "los catolicismos".

La obra está organizada en tres partes: Olhares do Centro-Oeste, Olhares do Nordeste y Olhares do Norte. La selección de estas regiones, siguiendo el criterio de división territorial establecido por el Instituto Brasileiro de Geografia e Estatística (IBGE), corresponde a tres cuartas partes del extenso territorio brasileño. Si bien no todos los estados de estas regiones están representados en los capítulos, sí lo está gran parte de ellos.

En Olhares do Centro-Oeste, los dos primeros capítulos tienen como eje común la vinculación entre catolicismo y los conflictos por la tierra en las décadas del '70 y '80. Por su parte, Vitale Joanoni Neto destaca el accionar de obispos, religiosos y laicos de las áreas de Juína y la prelacía de São Félix do Araguaia. Estos agentes pastorales organizaron Comunidades Eclesiales de Base (CEB's) y comisiones pastorales sustentadas en la Teología de la Liberación en defensa de los "pobres rurales". Del mismo modo, Luciene Aparecida Castravechi y Maria Henriqueta dos Santos Gomes abordan la ciudad de Santa Terezinha, comprendida en la prelacía de São Félix do Araguaia, en la que destacan el

\footnotetext{
1 RODRIGUES, Cândido y ZANOTTO, Gizele (organizadores) Catolicismos e sociabilidade intelectual no Brasil e na Argentina, EdUFMT, Cuiabá, 2013.

2 RODRIGUES Cândido; ZANOTTO, Gizele; CALDEIRA, Rodrigo Coppe (organizadores) Manifestações do Pensamento Católico na América do Sul, Fonte Editorial, São Paulo, 2015.
} 
trabajo del obispo catalán Pedro Casaldáliga ante la violencia y los conflictos con la empresa agropecuaria Companhia de Desenvolvimento do Araguaia (CODEARA).

En los dos capítulos siguientes el eje está puesto en Goiás. De este modo, Eduardo Gusmão de Quadros interpreta los conflictos intraeclesiásticos que ocurrieron entre los misioneros redentoristas y el obispo salesiano de Goiás luego de la "Revolución del 30". El nuevo escenario político alteró el equilibrio regional, acentuó los conflictos y abrió nuevas oportunidades, en especial luego de la decisión del interventor de retomar el proyecto de construcción de una nueva capital para el estado, la actual ciudad Goiânia. A su vez, el capítulo de Robson Rodrigues Gomes Filho toma las categorías de "experiencia" y "expectativa" de Reinhart Koselleck, y sigue atentamente la publicación de los redentoristas Santuário da Trindade entre 1922 y 1927. Allí advierte la elaboración singular que hicieron estos misioneros alemanes, habituales viajeros por Europa, San Pablo y Goiás, acerca del "progreso" y el "atraso".

En Olhares do Nordeste se aprecia la mayor cantidad de capítulos, con un total de ocho trabajos. En el caso de Irinéia Maria Franco dos Santos, la autora reflexiona sobre los cambios en la leyenda de la "Santa Fugitiva" en la localidad de Anadia (Alagoas) durante el siglo XIX. Allí percibe cómo se fue tejiendo una memoria mítica de "sincretismo afro-indígena-católico" que reservó lugares diferenciales en su construcción a la población blanca, afro e indígena.

El capítulo siguiente nos desplaza al estado de Ceará y Edianne dos Santos Nobre propone una lectura a contrapelo de la "historia oficial" del conocido "Milagro de Juazeiro" que dio protagonismo al sacerdote Cícero Romão Batista. La atención está puesta en la protagonista olvidada de dicho "milagro", la beata María de Araújo, dirigida espiritual del Padre Cícero. Asimismo, Francisco Régis Lopes Ramos estudia las diferentes narrativas que se construyeron sobre el Padre Cícero a lo largo del tiempo en la literatura de cordel. En esta literatura, de estrecho vínculo entre lo escrito y lo oral, identifica el contenido hagiográfico y sus variaciones de acuerdo a las circunstancias históricas. Como el autor sostiene, la memoria del "Santo de Juazeiro" se hace en múltiples temporalidades y soportes, y tratar con estas "imágenes" se asemeja a la manipulación de un caleidoscopio.

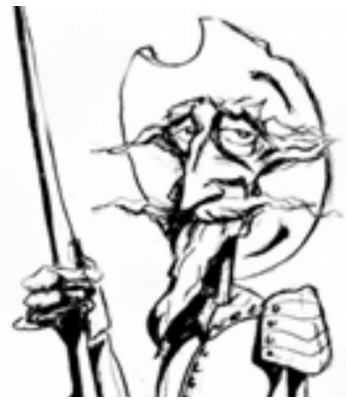

A continuación, Carlos André Silva de Moura enfatiza en el intercambio cultural e intelectual entre brasileños y lusitanos en las primeras décadas del siglo XX, desde una perspectiva de la circulación de las ideas. Indaga en el rol de los jesuitas expulsados de Portugal que se asentaron en Brasil, especialmente en aquellos que llevaron adelante diversos proyectos en la ciudad de Recife con el propósito de expandir el culto a "Nuestra Señora de Fátima".

Los dos capítulos siguientes están relacionados con los intelectuales y el imaginario del movimiento integralista. De este modo, Elynaldo Gonçalves Dantas presenta una lectura derridiana de la obra Integralismo e Catolicismo (1937), escrita por Gustavo Barroso, miembro de la Ação Integralista Brasileira (AIB). Dantas revela la intención de Barroso de buscar "sacralizar el integralismo" e "integralizar el catolicismo". A su vez, Michelle Reis de Macedo estudia la articulación entre catolicismo y el movimiento integralista entre las décadas del '50 y '60 por medio de los discursos y prácticas de la Patrulha Nacional Cristã (PNC) de Alagoas y los relatos de su dirigente Wanillo Galvão Barros. Allí destaca el papel de la PNC en la desestabilización y caída del gobierno de João Goulart (1964). 
En el cierre de la región del nordeste hay dos trabajos disímiles. Por un lado, Edilece Souza Couto investiga las hermandades, cofradías y órdenes terciarias en Salvador de Bahía entre finales del siglo XIX y comienzos de la República Velha. Especialmente profundiza en cómo afectaron en las prácticas de las asociaciones laicas las reformas urbanas en Bahía y los cambios en el catolicismo. Por otro lado, Iraneidson Santos Costa indaga sobre las prédicas de los "obispos proféticos nordestinos", un conjunto de prelados que se destacó por sus discursos incisivos, por su acción pastoral y por la denuncia de las estructuras sociales, económicas y políticas a lo largo de la segunda mitad del siglo XX.

En Olhares do Norte, Elisângela Socorro Maciel Soares examina el recorrido de la diócesis de Amazonas desde su fundación hasta mediados de los años veinte, destacando la impronta "romanizada" por la que estuvo signada desde sus comienzos. A continuación, Jaci Guilherme Vieira presenta la actuación de la Orden de San Benito y los problemas para instalarse en el valle del Rio Branco, actual estado de Roraima, debido a las características del lugar marcado por el aislamiento, las tierras monopolizadas por los coroneles y latifundistas, y el reparto de poder entre estos en el período de la República Velha. A su vez, Moisés Pereira da Silva evalúa la trayectoria del catolicismo en el espacio del actual estado de Tocantins, enfatizando en la Comissão Pastoral da Terra (CPT) y la actuación de uno de sus agentes pastorales, el sacerdote Josimo Moraes Tavares, asesinado en 1986. Finalmente, el trabajo de Marcos Vinicius de Freitas Reis explora el compromiso político-partidario de los católicos carismáticos en el estado de Amapá entre el año 2010 y 2014, distinguiendo las estrategias utilizadas en la elección de sus representantes como en la visión que dicho grupo tiene acerca de la política partidaria.

En suma, Olhares sobre os catolicismos... es un aporte para los investigadores que estudian el catolicismo brasileño porque brinda una mirada "desfolklorizada" de las regiones alejadas del eje San Pablo-Río de Janeiro, un relevo actual de las producciones de las universidades de estas regiones como también una contribución al conocimiento de las historiografías regionales. De igual modo, muestra las potencialidades de las redes de estudios en un país con dimensiones continentales y abre el camino a nuevas indagaciones. 